
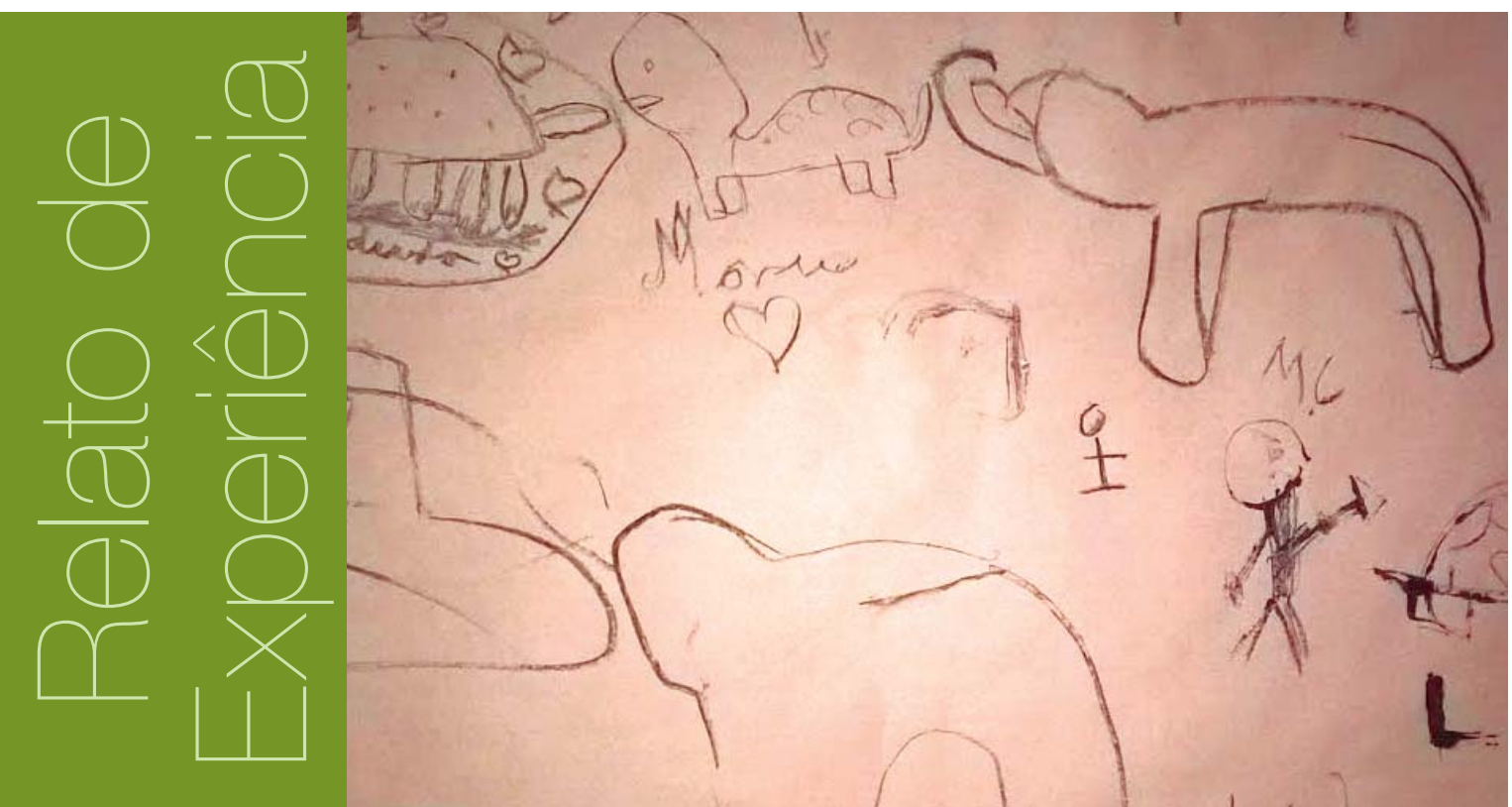

\title{
Exposição interativa como estratégia de valorização da história paleontológica regional
}

Andrerika Vieira L. Silva1 - andrerika.silva@iffarroupilha.edu.br Úrsula Adriane L. Ribeiro² - ursula.ribeiro@iffarroupilha.edu.br

\section{RESUMO}

Durante 0 ano de 2016, 0 Instituto Federal Farroupilha Câmpus Avançado Uruguaiana - RS desenvolveu uma série de exposições interativas "Caminhando com Gigantes", elaborada para crianças de 6 a 9 anos de idade, que abordaram a megafauna da última grande era do gelo, encerrada há aproximadamente 11 mil anos. Mais de 600 crianças participaram das atividades que contribuíram para a valorização da pré-história regional e aproximaram ainda mais a instituição das escolas do município.

\section{PALAVRAS-CHAVE}

Atividades interativas. Ensino de paleontologia. Megafauna Pleistocênica.

\section{ABSTRACT}

During the year 2016, the Farroupilha Federal Institute, Advanced Campus Uruguaiana developed the series of interactive exhibits "Walking with Giants" designed for children aged 6 to 9 years old, who addressed the megafauna of the last great ice age, which ended approximately 11,000 years ago. More than 600 children participated in activities that contributed to the valorization of regional prehistory and brought the campus closer to the city schools.

1 Licenciada em geografia. Mestre em Agricultura Tropical e Subtropical. Docente EBTT do Instituto Federal de Mato Grosso do Sul. 


\section{KEYWORDS}

Interactive activities. Paleontology teaching. Pleistocene Megafauna.

\section{Relato de experiência}

Este relato aborda a experiência da exposição "Caminhando com Gigantes" elaborada no ano de 2016, pelos servidores e estudantes do Câmpus Avançado Uruguaiana do Instituto Federal Farroupilha.

Uruguaiana se localiza no extremo oeste do estado do Rio Grande do Sul e apresenta rica história paleontológica, onde se destacam os fósseis da Megafauna Pleistocênica. Esses fósseis são encontrados em diversas áreas do município.

Do ponto de vista da história do planeta, o Pleistoceno é um passado recente, e muitos dos mamíferos característicos desta época têm parentes próximos na atualidade. Preguiças gigantes, mastodontes e gliptodontes são alguns exemplos de mamíferos da Megafauna.

Ubilla (2009) destaca que entre 11 mil e 8 mil anos atrás, 80\% dos grandes mamíferos (animais entre 40 e 1000 quilos) e a totalidade dos megamamíferos (animais com mais de 1000 quilos) se extinguiram na América. 0 motivo da extinção desses animais não é consenso entre os pesquisadores, mas as teorias mais aceitas são: mudanças climáticas, intervenção humana (caça predatória) ou até mesmo uma combinação desses fatores (COURTOISIE; FARIÑA, 2016).

As principais fontes de informações sobre vertebrados fósseis consultadas para esse projeto foram os artigos de Oliveira e Kerber (2009) e Kerber et al. (2014), sendo este último um amplo artigo de revisão sobre a formação Touro Passo existente no município, onde foram descritas as ocorrências de Megatérios, Gliptodontes, Pampatérios, Toxodontes, entre muitos outros mamíferos pleistocênicos. Também foram consultados os trabalhos de Courtoisie e Fariña (2016), Fariña, Vizcaíno e DeJuilis (2013)

Dallabona e Mendes (2004) discutem que é por meio da brincadeira que a criança satisfaz seus desejos e necessidades, pois reflete a maneira como a criança ordena e constrói o mundo. Desse modo, o lúdico é uma das maneiras mais eficazes de envolver as crianças nas atividades.

Considerando essas discussões, o principal objetivo do projeto foi desenvolver uma exposição interativa e lúdica sobre a Megafauna de Uruguaiana - RS, que valorizasse a experiência das crianças e sua interação com os animais da Megafauna.

Todas as atividades foram pensadas para crianças em fase de alfabetização, de 6 a 9 anos de idade, utilizando linguagem simples e, para valorizar a experiência sensorial, todas as crianças podiam manusear todos os objetos em exposição (rochas, réplicas, pintar os desenhos, entre outros).

A exposição foi organizada nas dependências do Câmpus e em uma sala em desuso pertencente à Prefeitura Municipal de Uruguaiana no centro da cidade. Estudantes e servidores do câmpus foram treinados para atuarem como monitores e a duração da visita foi de aproximadamente 40 minutos.

A exposição era iniciada por uma contação de história, que usava números desenhados nas escadas da instituição para fazer uma viagem ao passado, terminando no pleistoceno (sala da exposição). Para que as crianças seguissem a sequência correta de atividades, foi feito um caminho de patinhas coladas no chão.

Foi desenvolvido um mapa interativo da América do Sul com a localização de alguns megamamíferos e, ao clicar na figura de cada animal, a criança podia ouvir os sons emitidos por eles.

Os pequenos também puderam conhecer várias rochas e minerais e fazer pequenos experimentos, como conhecer a cor do traço de minerais e manipular fósseis e réplicas de fósseis.

Para que as crianças compreendessem o tamanho desses megamamíferos, partes dos animais (patas, dentes) foram reproduzidas em tamanho real por meio de desenhos e esculturas em gesso e isopor. Patas de mastodonte e de preguiça gigante foram desenhadas no chão e as crianças foram estimuladas a comparar o tamanho dos seus pés com o tamanho das patas dos animais (Figura 1). Essa atividade simples foi surpreendente para os pequenos, ajudando-os a compreender que animais tão grandes não precisavam subir em árvores para coletar alimentos, por exemplo. 
Figura 1: Crianças sobre da pata da preguiça- gigante.

Fonte: Autoria própria.

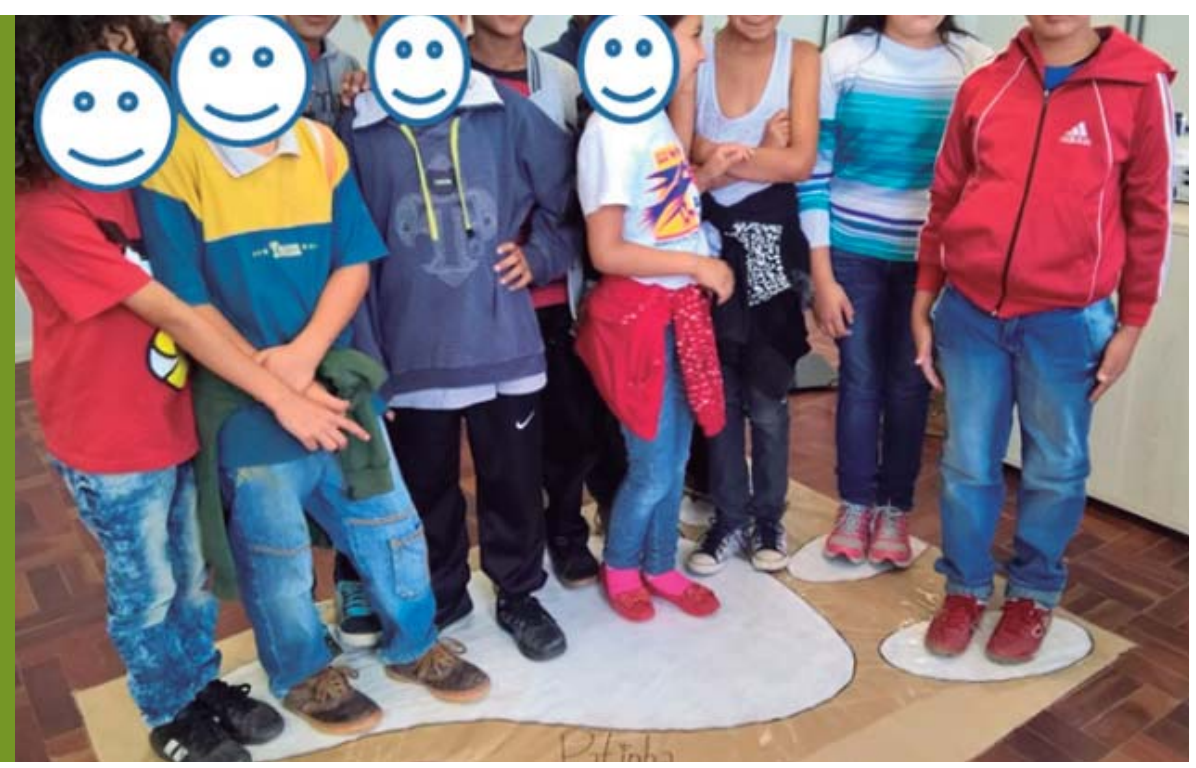

Outra atividade foi pensada para que os pequenos visitantes compreendessem a anatomia de um Gliptodonte. Nela, as crianças eram estimuladas a ajudar um filhote de Gliptodonte que tinha perdido sua carapaça. Cada criança escolhia uma osteoderma colorida de papel e fazia um desenho ou escrevia o próprio nome e colava no animal, para ajudá-lo a ter uma carapaça bem bonita. (Figura 2)

Figura 2: Crianças ajudando a montar uma carapaça para o gliptodonte.

Fonte: Autoria própria.

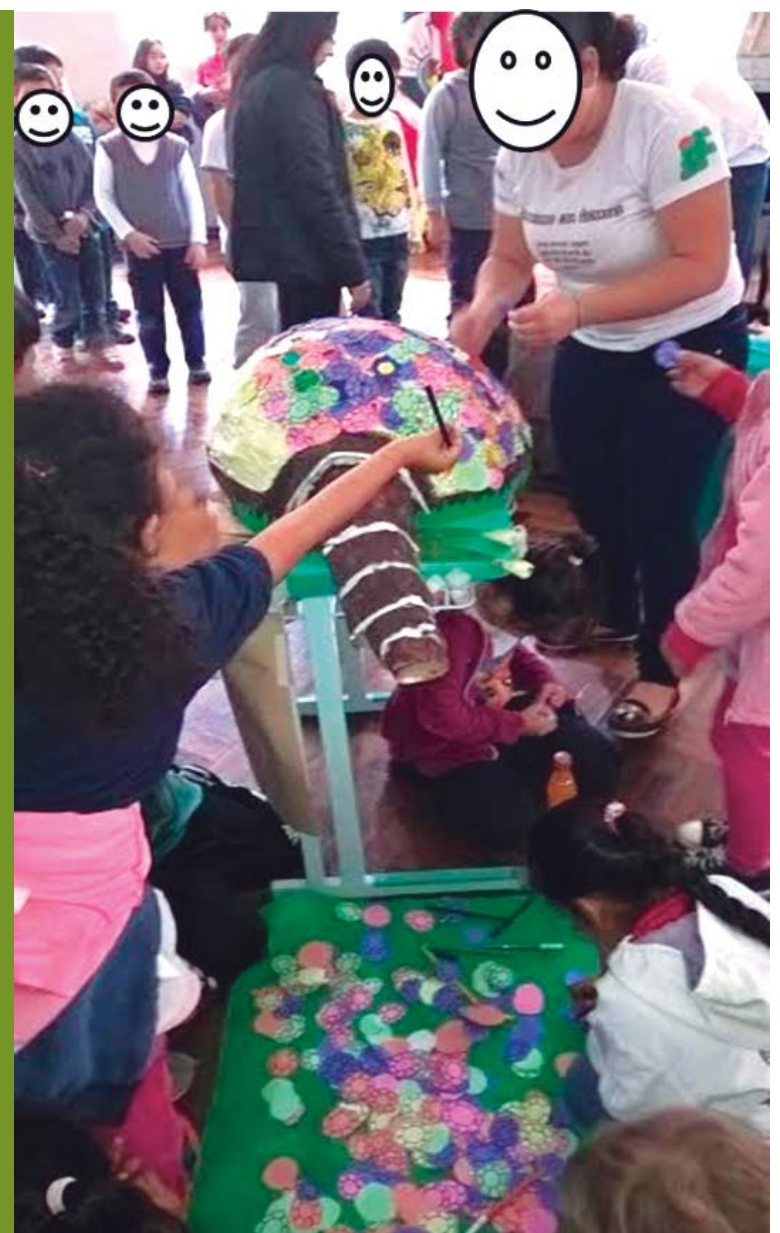

Para mostrar que muitos dos mamíferos da Megafauna tinham uma grande capacidade de cavar e fazer tocas montou-se um túnel (toca) do Pampatério com pneus velhos e tecidos, e foram coladas pegadas no seu interior. As crianças foram convidadas a entrar na toca e assim conhecer a casa do Pampatério. (Figura 3) 


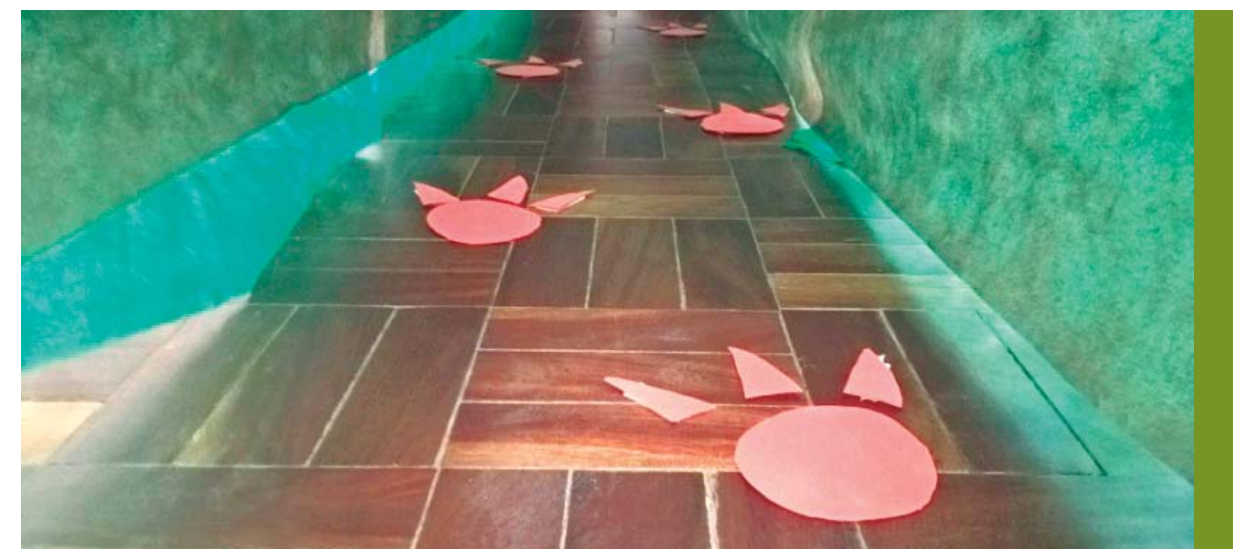

Figura 3: Detalhe interno da toca do Pampatério.

Fonte: Autoria própria.

Apesar de simples, essa atividade foi bem aceita pelas crianças, que ficaram surpresas ao encontrar patinhas dentro da toca.

Com o objetivo de enfatizar que populações humanas conviveram com esses animais e os retrataram em sua arte, foi montada uma "caverna" de pintura rupestre. A entrada da caverna tinha pinturas de animais feitas por "homens da caverna" de várias regiões do país e as crianças foram estimuladas a reconhecer os animais que ali estavam retratados. A "caverna" foi feita de papel e tecido, e as crianças puderam pintar os animais que conheceram na exposição. Os materiais usados para a pintura foram carvão vegetal e tinta guache (Figura 4).

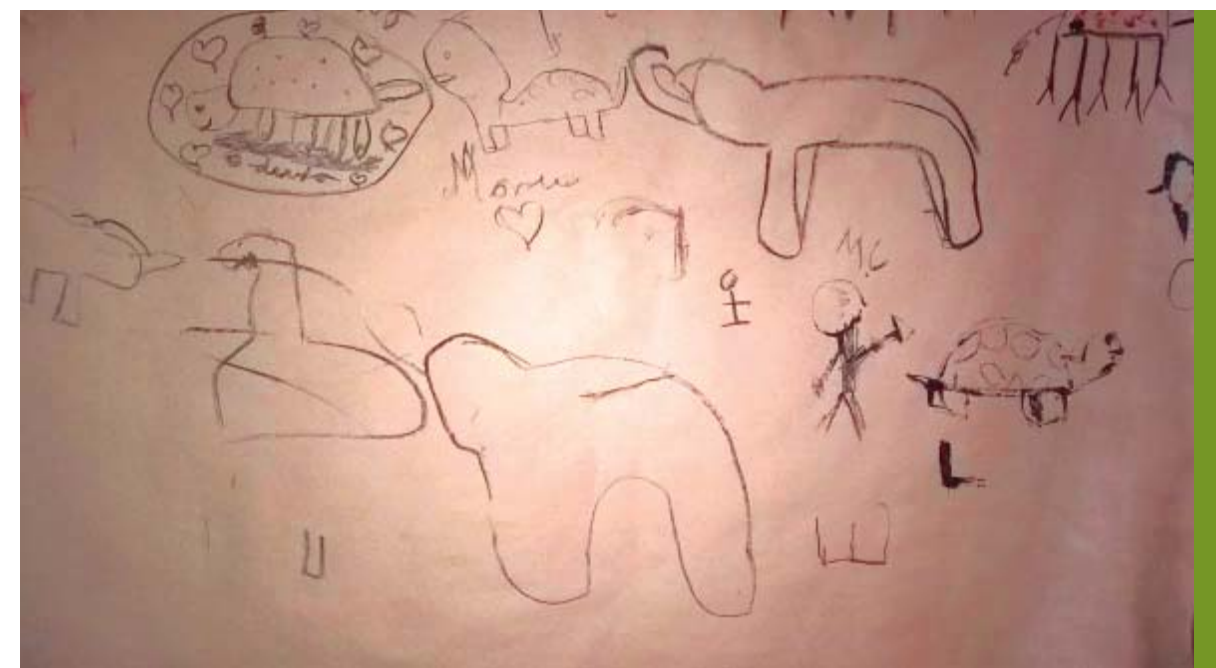

Figura 4: Desenhos feitos por crianças de 6 anos: Gliptodonte com corações, Mastodontes e homens desenhando.

Fonte: Autoria própria.

Destaca-se que as crianças tenderam a desenhar os homens junto aos animais, o que indica que elas compreenderam que esses animais conviveram com populações antigas.

Ao final da exposição, as crianças alfabetizadas foram convidadas a responder a um simples questionário de satisfação, onde deveriam pintar uma carinha correspondente à sua satisfação (Figura 5). Cada criança que respondia às questões colocava sua ficha numa caixinha. A caixa só foi aberta ao final das atividades.

\begin{tabular}{lll} 
VOCÊ GOSTOU? \\
$\substack{\text { LUE FOI MAIS } \\
\text { LEGAL? }}$ \\
\hline OQUE FOI MAIS \\
LEGAL?
\end{tabular}

Figura 5: Pesquisas respondidas a) em branco; b) criança pintou a carinha feliz e escreveu o "MAXOTODONTI"; e c) criança pintou a carinha e escreveu seu nome.

Fonte: Autoria própria. 
Foram respondidas 80 pesquisas de satisfação, das quais 11 estavam em branco e em 8 foi pintado mais de um rostinho. Das 61 crianças que responderam corretamente ao questionário, 59 marcaram o rostinho feliz, 1 marcou o rostinho indiferente e apenas 1 marcou o rostinho triste. A atividade favorita das crianças, de acordo com a pesquisa de satisfação, foi a de rochas e minerais, seguida pela pata do mastodonte e pela toca do Pampatério.

Aproximadamente 630 crianças do município de Uruguaiana participaram da exposição. Ao término das atividades, havia uma fila de espera de três escolas do município, além de convites de um museu local e de escolas de dois municípios vizinhos.

Conclui-se que a mostra "Caminhando com Gigantes" cumpriu os objetivos previamente estabelecidos de divulgar e valorizar a pré-história de Uruguaiana e estreitar os laços com a comunidade do entorno do Instituto Federal Farroupilha por meio da atividade de extensão.

\section{Referências}

COURTOISIE, A; FARIÑA, R. A. Historia Reciente del poblamiento remoto. Los hallazgos de Arroyo del Vizcaíno, Sauce, Biblioteca Canaria, 2016. 78 p. Disponível em: $<$ http://arroyodelvizcaino.org/archivos/Courtoisie-Fari\%C3\%B1a-2015-Historia-reciente-delpoblamiento-remoto-web.pdf>. Acesso em: 08 dez. 2016.

DALLABONA, S. R., MENDES, S. M. S. 0 lúdico na educação infantil. Revista de Divulgação Técnico-Científica do ICPG, v. 1, n. 4. p. 107-120, 2004.

FARIÑA, R. A.; VIZCAÍNO, S. F.; DEJUILIS, G. Megafauna - giant beasts of Pleistocene South America. Bloomington: Indiana University Press, 2013. 448 p.

KERBER, L. et al. Late Pleistocene vertebrates from Touro Passo Creek (Touro Passo Formation), southern Brazil: a review. Revista Mexicana de Ciencias Geológicas, v. 31, n. 2, p. 248-259, 2014.

OLIVEIRA, E. V.; KERBER, L. Paleontologia e aspectos geológicos das sucessões do final do Neógeno no sudoeste do Rio Grande do Sul. Journal of Geoscience, v. 5, n. 1, p. 21-34, jan.jjun. 2009.

UBILLA, M. Megafauna Pleistocênica: Evolução e extinção na América do Sul. In: DA-ROSA, A. A. (Org.). Vertebrados Fósseis de Santa Maria e Região. Santa Maria: Palloti, 2009. p. 303-320. 